\title{
Influence of Supply-Channel Velocity on Farm Delivery Meter Gate Flow Measurement
}

\author{
Daniel J. Howes, M.ASCE ${ }^{1}$; Charles M. Burt, M.ASCE ${ }^{2}$; and John M. Thorburn ${ }^{3}$
}

\begin{abstract}
The work presented here is an extension of previous papers that updated the calibration of round (Armco-type) meter gates (three sizes: $0.30,0.46$, and $0.61 \mathrm{~m}$ ), developed ratings for rectangular gates (two sizes: 0.46 and $0.61 \mathrm{~m}$ ) on round pipes, and examined errors and uncertainty related to using these devices for water discharge measurement. Previous works examined gate discharge ratings under low supply-channel flow velocity perpendicular to the gate discharge pipeline. Here, additional testing was conducted to test the hypothesis that higher velocities in the supply channel would show decreased meter gate flow compared to the low-velocity ratings, but that the published gate calibration method would still yield accurate flow-rate calculations. All testing was conducted in a test facility with the gate discharge pipe set perpendicular to the supply channel, as is common in field installations. Velocities up to $0.94 \mathrm{~m} / \mathrm{s}(3.1 \mathrm{ft} / \mathrm{s})$ were tested with the smaller gate and $0.66 \mathrm{~m} / \mathrm{s}(2.2 \mathrm{ft} / \mathrm{s})$ for all other gates. These velocities are on the upper end of velocities found in common earthen irrigation canals (and in many lined channels at the farm delivery level) in California. Interestingly, results indicate that the Froude number of the supply-channel flow did not have a statistically significant (at an $\alpha$-level of 0.01) influence on gate discharge coefficients. Discharge percent error and uncertainty were examined to compare the discharge coefficients presented in the literature to the discharge measured during the testing at different supply-channel velocities. Under recommended operating conditions, the uncertainty was within $\pm 5 \%$ without adjustments for supply-channel velocity. This extended work supports earlier recommendations that meter gates can be an accurate flow measurement device for farm water delivery flow measurement if installed and operated correctly.
\end{abstract}

Author keywords: Flow measurement; Irrigation; Canals; Gates; Uncertainty; Velocity.

\section{Introduction}

Calibrated meter gates are commonly used for on-off control and flow measurement at farm deliveries from canals. Initially, methods for calibrating commonly used Armco-type gates (round gates on round discharge pipes) were developed in the 1920s by Modesto Irrigation District and Fresno Irrigation District, California. Later, the U.S. Bureau of Reclamation (USBR) conducted a comprehensive calibration (Summers 1951). The USBR continued this work by rating rectangular gates on round pipes with two common gate sizes (Ball 1961). This research has been important in the establishment of some of the rating tables and installation and operational standards still used by irrigation districts to set flow rates to farms and estimate the volume of water delivered from an irrigation canal.

However, there were some limitations in this original calibration work. Uncertainty or accuracy in flow measurement was not specifically addressed. No additional formal investigations into the accuracy of the original rating tables had been conducted. The testing

${ }^{1}$ Associate Professor, Dept. of BioResource and Agricultural Engineering, Irrigation Training and Research Center, California Polytechnic State Univ., San Luis Obispo, CA 93407 (corresponding author). E-mail: djhowes@calpoly.edu

${ }^{2}$ Chairman, Irrigation Training and Research Center, California Polytechnic State Univ., San Luis Obispo, CA 93407. E-mail: cburt@ calpoly.edu

${ }^{3}$ Graduate Student, Irrigation Training and Research Center, Dept. of BioResource and Agricultural Engineering, California Polytechnic State Univ., San Luis Obispo, CA 93407. E-mail: jthorbur@calpoly.edu

Note. This manuscript was submitted on October 5, 2015; approved on December 6, 2016; published online on February 25, 2017. Discussion period open until July 25, 2017; separate discussions must be submitted for individual papers. This technical note is part of the Journal of Irrigation and Drainage Engineering, (C) ASCE, ISSN 0733-9437. configuration in the original studies (Summers 1951; Ball 1961) had the supply-channel flow parallel to the turnout pipe (i.e., flow from the supply went straight through the gate and into the farm delivery pipe), which differs from typical field configurations where the meter gate discharge pipe is set perpendicular to the supply-channel flow.

The authors recently conducted a study to update the gate calibrations and evaluate the uncertainty in flow measurement using round gates on round pipes (Howes and Burt 2015a) and square gates on round pipes (Howes and Burt 2015b) for commonly sized gates used for farm deliveries. These studies utilized testing configurations where the supply-channel flow was perpendicular to the discharge pipe, as discussed by Howes and Burt (2015a). In these studies, results were presented for a low supply-channel velocity as a baseline for improved gate ratings as well as installation and operational recommendations. This current paper is an extension to these previous two studies. Here, the work from these companion papers will be expanded to include the influence of supply-channel velocity on the meter gate ratings for both round and square gates on round pipelines.

The standard discharge equation for a submerged orifice is

$$
Q=C_{d} A_{o} \sqrt{2 g \Delta H}
$$

where $Q=$ flow rate $\left(\mathrm{m}^{3} / \mathrm{s}\right) ; C_{d}=$ coefficient of discharge; $A_{o}=$ net gate opened area $\left(\mathrm{m}^{2}\right) ; g=$ gravitational acceleration $\left(9.81 \mathrm{~m} / \mathrm{s}^{2}\right)$; and $\Delta H=$ head loss across the gate $(\mathrm{m})$. The coefficient of velocity $\left(C_{v}\right)$ has been neglected since the velocity of approach is close to zero because these gates are typically installed perpendicular to the supply-channel velocity streamlines.

Several studies have investigated flow through a side orifice under different supply-channel velocities. Swamee et al. (1993) found that the elementary discharge coefficient $\left(C_{d}\right)$ for free flow 
and a submerged rectangular sluice gate (rectangular gate with a rectangular channel downstream) was dependent on the ratios of upstream head and tailwater depth to gate opening. The equation used to compute the $C_{d}$ was based on water depths (upstream head) in the supply channel upstream of the gate, which were computed from ordinary differential equations. In the supply channel, the water depth is the lowest at the upstream side of the gate and increases to the downstream side, depending on the velocity within the supply channel, gate opening, etc. (Swamee et al. 1993). Simply put, the $C_{d}$ varies along the face of the gate as the upstream head varies.

Ghodsian (2003) simplified the discharge coefficient computation from Swamee et al. so that only the lowest upstream head (supply-channel water depth at the upstream side of the gate) was needed and Eq. (1) could be used directly to compute discharge. In this approach, there is no need to examine the varying water depth across the face of the gate. Ghodsian accomplished this by applying a correction within the $C_{d}$ equation based on the Froude number of the approach-channel flow. This correction increased the discharge coefficient at higher Froude numbers. In that study, the need for a positive $C_{d}$ correction (as opposed to a negative) is specifically related to location where the upstream head (in the supply channel) was taken. The water depth in the supply channel at the upstream edge of the gate decreases as the velocity (Froude number) increases. If Ghodsian (2003) had measured the upstream head for Eq. (1) on the downstream edge of the gate face, or on the supply-channel depth further upstream, the correction factor would likely have reduced the $C_{d}$.

This was the case in two recent studies examining the coefficient of discharge for rectangular (Hussain et al. 2011) and circular (Hussain et al. 2010) sharp-crested orifices under free-flow conditions. These studies, which based the $C_{d}$ on the supply-channel depth away from the face of the orifice, found that the Froude number in the approach channel and the ratio of channel width to opening width influenced $C_{d}$. The $C_{d}$ was lower at higher Froude numbers. While no work was found examining the approachchannel velocity on the discharge of meter gates (or any gates supplying pipelines), the authors hypothesize that higher supplychannel approach velocities and Froude numbers will reduce the gate discharge compared to what would be predicted using the low channel-velocity coefficients presented in the companion papers.

\section{Procedures}

The meter gate testing facility and testing scenarios for the round (Armco-type) gates are discussed in Howes and Burt (2015a) and the testing scenarios for rectangular gates on round discharge pipes are discussed in Howes and Burt (2015b). To briefly summarize the testing facility setup, it consisted of a 1.21-m-wide by 1.83 -m-high rectangular flume with a supply capacity of $0.85 \mathrm{~m}^{3} / \mathrm{s}$. The flow rate into the supply channel was adjusted using a variable frequency drive on the motor for the supply pump. Meter gates were installed so the pipeline supplied through the gate was perpendicular to the flume. The water depth in the supply canal was varied using an adjustable oblique weir downstream of the meter gate. More details including drawings of the testing facility are provided by Howes and Burt (2015a).

The flow rate in the supply channel was measured using a $0.762 \mathrm{~m}$ McCrometer UltraMag magnetic meter (McCrometer, Hemet, California) attached to the pipeline supplying the channel. The supply-channel velocity $\left(V_{1}\right)$ was computed based on the flow rate in the channel and the flow area computed based on the water depth $\left(d_{1}\right)$ in the supply channel measured just upstream of the gate and the channel width $(1.21 \mathrm{~m})$. The supply channel Froude number $\left(F_{1}\right)$ was computed as

$$
\mathrm{F}_{1}=\frac{V_{1}}{\sqrt{g d_{1}}}
$$

where subscript 1 identifies parameters upstream of the gate in the supply channel. The depth in the upstream supply channel $\left(d_{1}\right)$ is equal to the upstream head above the top of the turnout pipe $\left(H_{1}\right)$ plus the gate diameter (D) plus the distance from the bottom of the pipe to the channel bottom. A total of five different gates were tested in this evaluation. Three commonly used round canal gate (Armco-type) sizes [0.30 m (12 in.), $0.46 \mathrm{~m}$ (18 in.), and $0.61 \mathrm{~m}$ (24 in.)] were evaluated. These gates are the same design that was originally tested by Summers (1951), which are currently manufactured and were provided by Fresno Valves and Casting (Selma, California). Two commonly used rectangular canal gate sizes [0.46 m (18 in.) and $0.61 \mathrm{~m}$ (24 in.)] were examined under various conditions. These rectangular gates were manufactured by Mechanical Associates (Visalia, California) and provided by San Luis Canal Company (Dos Palos, California) for the testing. For each of these gates, upstream head, downstream head, gate openings, and supply-channel velocities were varied.

Table 1 summarizes the supply-channel variable ranges (depth, velocity, and Froude numbers) utilized as part of the meter gate evaluation under variable supply-channel velocity. Additional variables not given in Table 1 but summarized by Howes and Burt (2015a, b) included upstream head above the top of the turnout pipe $\left(H_{1}\right)$ and head loss measured at the $0.305 \mathrm{~m}$ stilling well location $(\Delta H)$. The relative approach head is the head above the bottom of the pipeline defined as $\left(H_{1}+D\right)$, where $D$ is the pipe diameter. The supply-channel velocity upstream of the meter gate varied between 0.071 and $0.941 \mathrm{~m} / \mathrm{s}(0.23$ and $3.09 \mathrm{ft} / \mathrm{s}$, respectively). A total of 1,025 data points were collected and used for this portion of the evaluation. The maximum flow possible in the Cal Poly flume was $0.85 \mathrm{~m}^{3} / \mathrm{s}(30 \mathrm{cuft} / \mathrm{s})$, so the maximum velocity was limited for the larger gate sizes because of minimum depths that could be tested. Thereby, the highest velocities and Froude numbers occurred at the lowest upstream depth scenarios for the smaller gate sizes.

Most irrigation distribution canals in California are earthen, and typically have velocities less than $0.91 \mathrm{~m} / \mathrm{s}(3 \mathrm{ft} / \mathrm{s}$ ). Concrete (or other lined) canals can have velocities greater than this, although many used for irrigation deliveries remain at $0.91 \mathrm{~m} / \mathrm{s}(3 \mathrm{ft} / \mathrm{s})$ or less (Scobey 1939). Therefore, even with the limited testing velocities, the results presented here will be applicable for many (if not most) meter gate installations.

The coefficient of discharge $\left(C_{d}\right)$ was evaluated by rearranging Eq. (1) as follows:

$$
C_{d}=\frac{Q}{A_{o} \sqrt{2 g \Delta H}}
$$

where $Q=$ measured flow rate through the meter gate; $A_{o}=$ meter gate opening area; and $\Delta H=$ head loss across the gate measured as the difference between the water depth in the supply channel and at a tap location $0.305 \mathrm{~m}$ downstream from the face of the gate. $C_{d}$ is computed for each test and is used as the basis of the evaluation. Measurement procedures and equipment for $Q, A_{o}$, and $\Delta H$ are discussed by Howes and Burt (2015a). 
Table 1. Range of Supply-Channel Depths, Velocity, and Froude Numbers Evaluated for Each Gate Type and Size

\begin{tabular}{|c|c|c|c|c|c|}
\hline Gate type $^{\mathrm{a}}$ & $\begin{array}{c}\text { Nominal } \\
\text { gate size }(\mathrm{m})\end{array}$ & $\begin{array}{c}\text { Relative } \\
\text { upstream head }\end{array}$ & $\begin{array}{l}\text { Upstream channel } \\
\text { depth }\left(d_{1}\right) \text { range }(\mathrm{m})\end{array}$ & $\begin{array}{l}\text { Upstream channel velocity } \\
\left(V_{1}\right) \text { range }(\mathrm{m} / \mathrm{s})\end{array}$ & $\begin{array}{l}\text { Upstream channel } \\
\mathrm{F}_{1} \text { range }\end{array}$ \\
\hline Round & 0.3 & Low & $0.789-0.865$ & $0.078-0.941$ & $0.027-0.309$ \\
\hline Round & 0.3 & Middle & $1.078-1.133$ & $0.120-0.633$ & $0.036-0.193$ \\
\hline Round & 0.3 & High & $1.318-1.453$ & $0.075-0.520$ & $0.020-0.145$ \\
\hline Round & 0.3 & Very high & $1.670-1.721$ & $0.075-0.404$ & $0.018-0.099$ \\
\hline Round & 0.46 & Very low & $0.813-0.902$ & $0.122-0.769$ & $0.043-0.259$ \\
\hline Round & 0.46 & Low & $1.014-1.340$ & $0.255-0.693$ & $0.078-0.220$ \\
\hline Round & 0.46 & Middle & $0.597-1.305$ & $0.071-0.558$ & $0.020-0.160$ \\
\hline Round & 0.46 & Very high & $1.416-1.562$ & $0.081-0.461$ & $0.022-0.121$ \\
\hline Round & 0.61 & Very low & $1.019-1.114$ & $0.157-0.658$ & $0.050-0.201$ \\
\hline Round & 0.61 & Low & $1.164-1.284$ & $0.164-0.561$ & $0.048-0.165$ \\
\hline Round & 0.61 & Middle & $1.343-1.467$ & $0.083-0.509$ & $0.022-0.138$ \\
\hline Round & 0.61 & High & $1.513-1.743$ & $0.086-0.454$ & $0.022-0.118$ \\
\hline Rectangular & 0.46 & Very low & $0.841-0.857$ & $0.090-0.739$ & $0.025-0.256$ \\
\hline Rectangular & 0.46 & Low & $0.932-1.030$ & $0.105-0.581$ & $0.033-0.184$ \\
\hline Rectangular & 0.46 & Middle & $1.067-1.340$ & $0.134-0.474$ & $0.039-0.142$ \\
\hline Rectangular & 0.46 & High & $1.194-1.311$ & $0.127-0.498$ & $0.036-0.140$ \\
\hline Rectangular & 0.46 & Very high & $1.384-1.545$ & $0.085-0.417$ & $0.023-0.108$ \\
\hline Rectangular & 0.61 & Very low & $1.013-1.199$ & $0.090-0.657$ & $0.025-0.208$ \\
\hline Rectangular & 0.61 & Low & $1.116-1.321$ & $0.107-0.481$ & $0.030-0.138$ \\
\hline Rectangular & 0.61 & Middle & $1.373-1.437$ & $0.079-0.521$ & $0.021-0.142$ \\
\hline Rectangular & 0.61 & High & $1.481-1.641$ & $0.083-0.471$ & $0.022-0.123$ \\
\hline
\end{tabular}

${ }^{a}$ Round gate type refers to the Armco-type gate.

\section{Results and Discussion}

The goal of this evaluation was to determine if some correction may be necessary for rated meter gate flow with higher velocities in the supply channel. Results shown by Howes and Burt (2015a, b) indicated that under certain conditions, namely at low gate openings (less than 25\%) and very low upstream head conditions (less than 0.5 times the pipe diameter), the $C_{d}$ values were inconsistent and were excluded from the analysis. Meter gates should not be used under those conditions if accurate flow measurement is needed. As in these companion papers, tests conducted under these conditions were excluded from the analysis here.

Figs. 1(a-e) shows the relationship between $C_{d}$ and $\mathrm{F}_{1}$. Visibly, there is no clear relationship between $C_{d}$ and $\mathrm{F}_{1}$ for any of the gates tested. As previously mentioned, the maximum velocity and $F_{1}$ were limited by the testing facilities so it is possible that a definitive influence may occur with higher velocities in the channel.

To examine the potential influences on $C_{d}$, a multiple regression analysis using a model similar to that used in Howes and Burt (2015a) with the addition of the supply channel Froude number $\left(F_{1}\right)$ was evaluated using the model:

$$
\begin{aligned}
\hat{C}_{d}= & \beta_{6}\left(\frac{A_{o}}{A_{p}}\right)^{3}+\beta_{5}\left(\frac{A_{o}}{A_{p}}\right)^{2}+\beta_{4}\left(\frac{A_{o}}{A_{p}}\right)+\beta_{3}\left(\frac{H_{1}+D}{D}\right) \\
& +\beta_{2}\left(\frac{\Delta H}{H_{1}}\right)+\beta_{1}\left(\mathrm{~F}_{1}\right)+\beta_{0}
\end{aligned}
$$

where $\hat{C}_{d}=$ predicted discharge coefficient; $\beta_{0}-\beta_{6}=$ regression coefficients; $A_{o} / A_{p}=$ relative gate opening; $\left(H_{1}+D\right) / D=$ relative upstream approach head; $D=$ turnout pipe diameter; $\Delta H / H_{1}=$ relative change head loss, and $F_{1}=$ supply-channel Froude number. Residual analysis was used to confirm the assumptions (normality, homoscedasticity, and independence of the errors) required for the multiple regression. The multiple regression coefficients for Eq. (4) and corresponding $p$-values for each gate size tested are provided in Table 2.

The $p$-values for the $F_{1}$ predictor are greater than 0.01 , indicating that the velocity in the supply channel may not influence $C_{d}$ at an $\alpha$-level of 0.01 . The $p$-values for the round (Armco-type) gates are less than 0.05. Since the Froude numbers examined in this study were limited by the testing setup, there could be a more significant influence at $F_{1}$ greater than those tested here. The coefficients shown for the $F_{1}$ predictor are negative for all but the $0.30-\mathrm{m}$ (12-in.) gate. This indicates that this predictor could have a negative influence on $C_{d}$, which supports the originally hypothesized but does not provide conclusive evidence.

While the $p$-value indicates if a parameter has an influence on $C_{d}$, it does not explain how much influence. Results in the companion papers indicated that $\left(H_{1}+D\right) / D$ and $\Delta H / H_{1}$ had no significant influence on $C_{d}$. Examination of the influence of $\left(H_{1}+D\right) / D, \Delta H / H_{1}$, and $\mathrm{F}_{1}$, a second model was used [Eq. (5)] and the adjusted $R^{2}$ values were compared between Eqs. (4) and (5)

$$
\hat{C}_{d}=\beta_{10}\left(\frac{A_{o}}{A_{p}}\right)^{3}+\beta_{9}\left(\frac{A_{o}}{A_{p}}\right)^{2}+\beta_{8}\left(\frac{A_{o}}{A_{p}}\right)+\beta_{7}
$$

Table 3 provides Eq. (5)'s multiple regression model constants and adjusted $R^{2}$ values after removing relative head, relative change in head, and supply-channel Froude number. There is very little difference between Eq. (4)'s and Eq. (5)'s adjusted $R^{2}$ values, indicating that the parameters removed from the regression model have a minimal effect on the computed $C_{d}$. Multiplicative nonlinear regression models similar to those used by Oskuyi and Salmasi (2012) were also examined. The nonlinear models confirmed the results of the linear models [Eqs. (4) and (5)] that indicated relative upstream approach head, relative change in head, and supplychannel Froude number had minimal effect on $C_{d}$. Since nonlinear regression resulted in less accuracy in predicting $C_{d}$, compared to Eq. (5), these results are not shown.

The authors recommend caution if multiple regression models [Eq. (4) or (5)] are used to compute the $C_{d}$ values. Utilizing predictor values outside of those used to develop the regression coefficients can lead to significant errors. $C_{d}$ values developed by gate openings in the companion papers should be used as described in those works (Howes and Burt 2015a, b). 

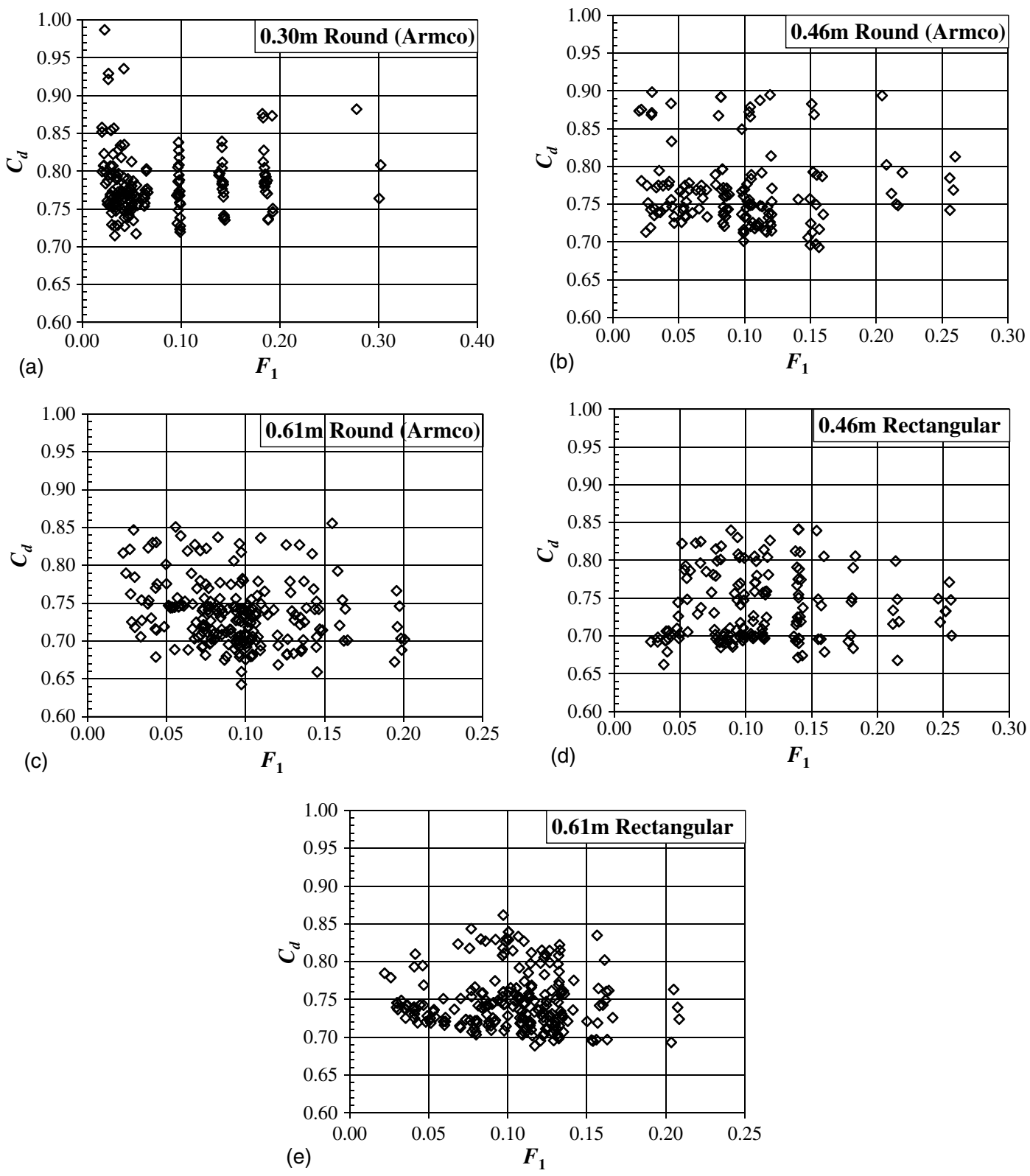

Fig. 1. Coefficient of discharge $\left(C_{d}\right)$ related to the Froude number $\left(\mathrm{F}_{1}\right)$ in the upstream supply channel for (a-c) three round (Armco-Type) gates and (d and e) two rectangular gates

Table 2. Eq. (4) Multiple Regression Coefficients and Corresponding $p$-Values for Each Gate Size Tested

\begin{tabular}{|c|c|c|c|c|c|c|c|c|c|c|c|}
\hline \multirow[b]{2}{*}{ Predictor } & \multirow[b]{2}{*}{ Coefficient } & \multicolumn{2}{|c|}{$0.30-\mathrm{m}$ round $^{\mathrm{a}}$} & \multicolumn{2}{|c|}{$0.46-\mathrm{m}$ round $^{b}$} & \multicolumn{2}{|c|}{$0.61-\mathrm{m}$ round $^{\mathrm{c}}$} & \multicolumn{2}{|c|}{$0.46-\mathrm{m}$ rectangular ${ }^{\mathrm{d}}$} & \multicolumn{2}{|c|}{$0.61-\mathrm{m}$ rectangular ${ }^{\mathrm{e}}$} \\
\hline & & Coefficient & $p$-value & Coefficient & $p$-value & Coefficient & $p$-value & Coefficient & $p$-value & Coefficient & $p$-value \\
\hline$\left(A_{o} / A_{p}\right)^{3}$ & $\beta_{6}$ & -1.324 & 0.000 & -1.041 & 0.000 & -0.589 & 0.001 & -1.484 & 0.000 & -0.299 & 0.049 \\
\hline$\left(A_{o} / A_{p}\right)^{2}$ & $\beta_{5}$ & 2.745 & 0.000 & 2.555 & 0.000 & 1.536 & 0.000 & 3.014 & 0.000 & 0.881 & 0.002 \\
\hline$\left(A_{o} / A_{p}\right)$ & $\beta_{4}$ & -1.911 & 0.000 & -2.031 & 0.000 & -1.359 & 0.000 & -1.733 & 0.000 & -0.679 & 0.000 \\
\hline$\left(H_{1}+D\right) / D$ & $\beta_{3}$ & -0.001 & 0.686 & -0.016 & 0.000 & -0.022 & 0.000 & -0.005 & 0.327 & -0.002 & 0.817 \\
\hline$\Delta H / H_{1}$ & $\beta_{2}$ & 0.023 & 0.008 & 0.003 & 0.721 & 0.007 & 0.306 & 0.006 & 0.657 & -0.013 & 0.213 \\
\hline $\mathrm{F}_{1}$ & $\beta_{1}$ & 0.054 & 0.031 & -0.086 & 0.022 & -0.108 & 0.023 & -0.047 & 0.255 & -0.051 & 0.371 \\
\hline Constant & $\beta_{0}$ & 1.213 & 0.000 & 1.293 & 0.000 & 1.155 & 0.000 & 0.995 & 0.000 & 0.890 & 0.000 \\
\hline
\end{tabular}

Note: $p$-values $>0.01$ indicate the variable does not influence $C_{d}$ at an $\alpha$-level $=0.01$.

${ }^{\text {a Adjusted }} R^{2}=75.9 \%$.

${ }^{\mathrm{b}}$ Adjusted $R^{2}=85.5 \%$.

${ }^{\mathrm{c}}$ Adjusted $R^{2}=77.3 \%$.

${ }^{\mathrm{d}}$ Adjusted $R^{2}=77.7 \%$.

${ }^{\mathrm{e}}$ Adjusted $R^{2}=34.9 \%$. 
Table 3. Eq. (5) Multiple Regression Coefficients and Corresponding $p$-Values for Each Gate Size Tested

\begin{tabular}{|c|c|c|c|c|c|c|c|c|c|c|c|}
\hline \multirow[b]{2}{*}{ Predictor } & \multirow[b]{2}{*}{ Coefficient } & \multicolumn{2}{|c|}{$0.30-\mathrm{m}$ round $^{\mathrm{a}}$} & \multicolumn{2}{|c|}{$0.46-\mathrm{m}$ round $^{\mathrm{b}}$} & \multicolumn{2}{|c|}{$0.61-\mathrm{m}$ round $^{\mathrm{c}}$} & \multicolumn{2}{|c|}{$0.46-\mathrm{m}$ rectangular ${ }^{\mathrm{d}}$} & \multicolumn{2}{|c|}{$0.61-\mathrm{m}$ rectangular ${ }^{\mathrm{e}}$} \\
\hline & & Coefficient & $p$-value & Coefficient & $p$-value & Coefficient & $p$-value & Coefficient & $p$-value & Coefficient & $p$-value \\
\hline$\left(A_{o} / A_{p}\right)^{3}$ & $\beta_{10}$ & -1.302 & 0.000 & -1.023 & 0.000 & -0.579 & 0.002 & -1.480 & 0.000 & -0.290 & 0.055 \\
\hline$\left(A_{o} / A_{p}\right)^{2}$ & $\beta_{9}$ & 2.703 & 0.000 & 2.522 & 0.000 & 1.516 & 0.000 & 3.003 & 0.000 & 0.865 & 0.002 \\
\hline$\left(A_{o} / A_{p}\right)$ & $\beta_{8}$ & -1.886 & 0.000 & -2.014 & 0.000 & -1.348 & 0.000 & -1.728 & 0.000 & -0.670 & 0.000 \\
\hline Constant & $\beta_{7}$ & 1.223 & 0.000 & 1.259 & 0.000 & 1.119 & 0.000 & 0.986 & 0.000 & 0.877 & 0.000 \\
\hline
\end{tabular}

Note: $p$-values $>0.01$ indicate the variable does not influence $C_{d}$ at an $\alpha$-level $=0.01$.

${ }^{\text {a Adjusted }} R^{2}=74.2 \%$.

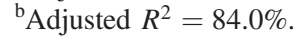

${ }^{\mathrm{c}}$ Adjusted $R^{2}=75.7 \%$.

${ }^{\mathrm{d}}$ Adjusted $R^{2}=77.8 \%$.

${ }^{\mathrm{e}}$ Adjusted $R^{2}=35.0 \%$.
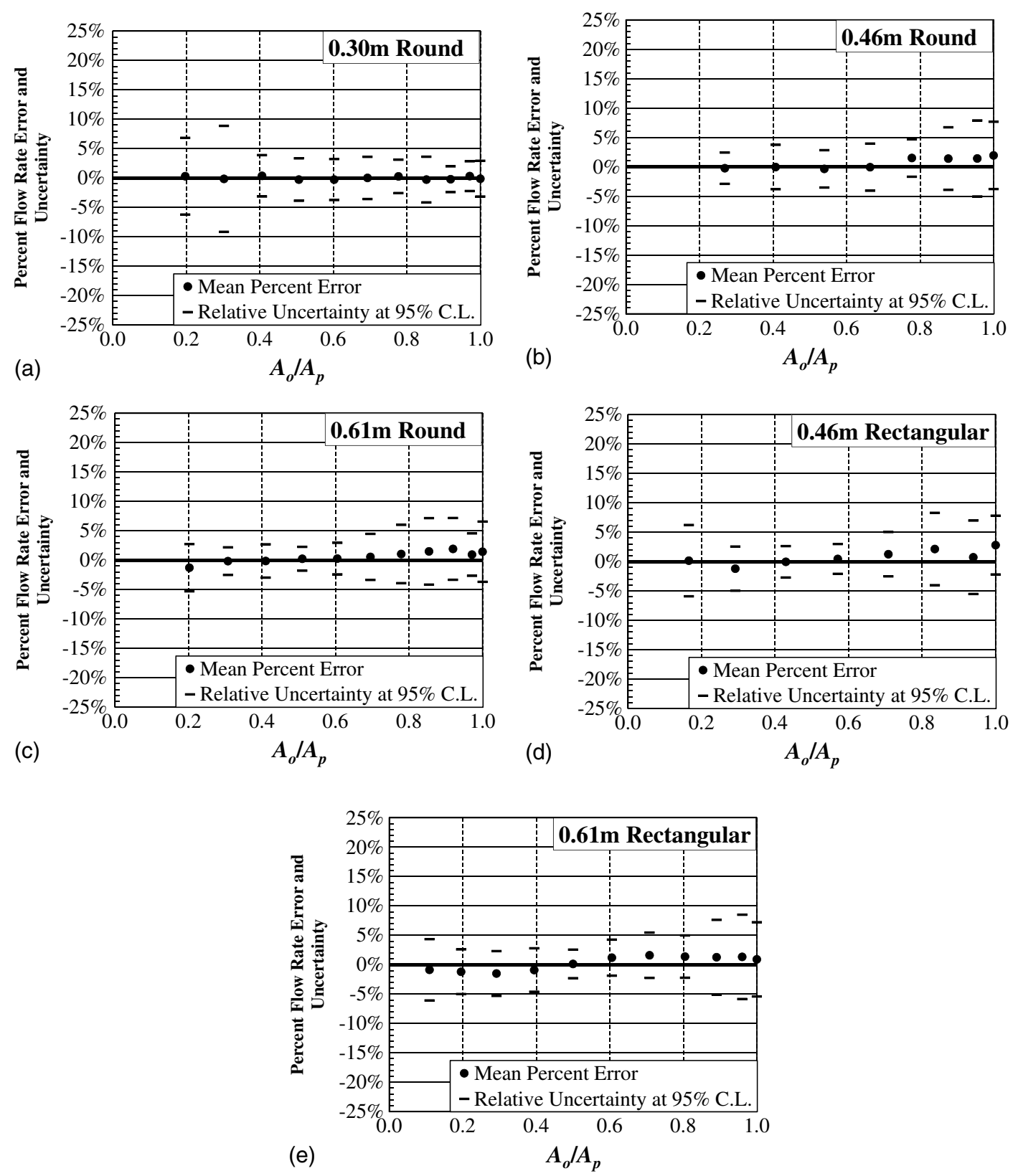

Fig. 2. Percent flow rate error and uncertainty using $C_{d}$ values recommended for (a-c) round (Armco-type) gates (Howes and Burt 2015a) and (d and e) rectangular gates on round pipes (Howes and Burt 2015b) using results from all supply-channel velocities 
The additional tests at the higher channel velocities were combined with the original low channel-velocity tests from the companion papers to examine the mean percent error and relative expanded (95\% confidence level) uncertainty. The percent error was computed by comparing the computed flow through the meter gate using $C_{d}$ values from the companion papers to the measured flow through the meter gates. Figs. 2(a-e) shows the results of this evaluation. The uncertainty is similar to those in the companion papers for recommended meter gate operation (within a $\pm 5 \%$ with gate openings typically between 25 and $75 \%$ ). However, the uncertainty increased for the 0.46 and $0.61 \mathrm{~m}$ round and rectangular gates at gate openings above $75 \%$. In general the relative error also increased slightly at these gate openings, indicating that the recommended $C_{d}$ values resulted in a slight overestimation of the flow rate $(0-2 \%)$. This indicates that although overall the higher supply-channel velocity did not have a significant influence, at larger gate openings (above 75\%) there may be greater impact. This could be a result of increased variability in measurements due to hydraulics at the entrance of the pipe (which is why it is recommended to design meter gates to operate between 25 and $75 \%$ open).

\section{Conclusion}

Research was conducted to test commonly sized meter gates (round gates on round pipes and square gates on round pipes) with supply channel flow perpendicular to the meter gate pipe. Prior calibration testing by others had testing setups with supply flows straight into the pipelines, which is uncommon in field installations. Two earlier papers presented improved calibration results for the gates tested with low supply-channel velocities (Howes and Burt 2015a, b). Additional testing results with higher supply-channel velocities perpendicular to the pipeline were shown here. The objective of this analysis was to test the hypothesis that increased supplychannel velocity would have a negative effect on the discharge coefficient, thus resulting in an overestimation of flow if using the baseline calibration results shown in the companion papers. Common supply-channel velocities up to $0.94 \mathrm{~m} / \mathrm{s}(3.1 \mathrm{ft} / \mathrm{s})$ for the smaller gates and approximately $0.66 \mathrm{~m} / \mathrm{s}(2.2 \mathrm{ft} / \mathrm{s})$ for larger gates were examined.

The average trend shown in the multiple regression analysis indicated that indeed the higher supply-channel velocities negatively influenced the discharge coefficient. However, the meter gate flow was not significantly influenced by supply-channel velocities perpendicular to the meter gate discharge pipe. Therefore, no correction to the baseline round and rectangular meter gate calibration presented in companion papers for supply-channel flow velocity or
Froude number is recommended. Future testing at higher than common velocities may indicate a statistically significant influence of supply-channel Froude number on gate flow.

\section{Acknowledgments}

This work was funded by a grant (13-01-005) from the California State University Agricultural Research Institute (CSU ARI). The authors would also like to acknowledge the support provided by San Luis Canal Company (Dos Palos, California) and Fresno Valves and Casting (Selma, California) through the donation of the gates tested in this work. This work could not have been completed without the hours of work provided by Cal Poly water engineering and irrigation graduate students and construction efforts by Irrigation Training and Research Center (ITRC) student employees from the BioResource and Agricultural Engineering Department.

\section{References}

Ball, J. W. (1961). "Flow characteristics and limitations of screw lift vertical metergates." Rep. No. HYD-471, U.S. Dept. of the Interior, Bureau of Reclamation, Denver.

Ghodsian, M. (2003). "Flow through side sluice gate." J. Irrig. Drain. Eng., 10.1061/(ASCE)0733-9437(2003)129:6(458), 458-463.

Howes, D. J., and Burt, C. M. (2015a). "Accuracy of round meter gates for on-farm deliveries." J. Irrig. Drain. Eng., 10.1061/(ASCE)IR.1943 -4774.0000930, 04015032.

Howes, D. J., and Burt, C. M., (2015b). "Rating rectangular farm delivery meter gates for flow measurement." J. Irrig. Drain. Eng., 10.1061 /(ASCE)IR.1943-4774.0000931, 04015033.

Hussain, A., Ahmad, Z., and Asawa, G. L. (2010). "Discharge characteristics of sharp-crested circular side orifices in open channels." Flow Meas. Instrum, 21(3), 418-424.

Hussain, A., Ahmad, Z., and Asawa, G. L. (2011). "Flow through sharp-crested rectangular side orifices under free flow condition in open channels." Agric. Water Manage., 98(10), 1536-1544.

Oskuyi, N. N., and Salmasi, F. (2012). "Vertical sluice gate discharge coefficient." J. Civ. Eng. Urbanism, 2(3), 108-114.

Scobey, F. C. (1939). "Flow of water in irrigation and similar canals." U.S. Dept. of Agriculture, Washington, DC.

Summers, J. B. (1951). "Flow characteristics and limitations of Armco meter gates; August 5, 1951." Rep. No. HYD-314, U.S. Dept. of the Interior, Bureau of Reclamation, Branch of Design and Construction, Denver.

Swamee, P. K., Pathak, S. K., and Ali, M. S. (1993). "Analysis of rectangular side sluice gates." J. Irrig. Drain. Eng., 10.1061/(ASCE)0733 -9437(1993)119:6(1026), 1026-1035. 